\title{
EFEITOS DE ÁCIDO FERÚLICO EM INTERAÇÕES COM DENSIDADES DE SOJA E CARURU ${ }^{1}$
}

\author{
ELEMAR VOLL ${ }^{2}$
}

\begin{abstract}
Um experimento foi conduzido sob condições de casade-vegetação com o objetivo de avaliar os efeitos de ácido ferúlico (ácido 4-hidróxi-3-metóxi-t-cinâmico) sobre combinações de densidades de soja [Glycine max (L.) Merr. cv. Bragg] com caruru (Amaranthus retrof lexus L.) num modelo substitutivo de competição. As proporções de plantas de soja para caruru estabelecidas por vaso foram de 4:0, 3:2, 2:4, 1:6 e 0:8. As doses de ácido ferúlico foram de zero, 500 e 1000 $\mathrm{ppm}$. O delineamento experimental foi o de blocos ao acaso, com quatro repetições. A duração do experimento foi de 33 dias. Houve atraso de dois e três dias na emergência da soja, nas doses de 500 e 1000 ppm de ácido ferúlico, respectivamente. A altura das plantas de soja aumentou nas menores
\end{abstract}

RESUMO

proporções de soja:caruru e com doses crescentes de ácido ferúlico, observando-se o oposto para o caruru. Reduções na biomassa seca por planta da parte aérea e das raízes de soja foram observadas com aumentos de proporção de plantas de soja, ao contrário do caruru. Doses crescentes de ácido ferúlico reduziram a biomassa seca da parte aérea por planta de caruru, reduzindo a produção total relativa. A competição intra-específica em cultura pura foi maior em soja do que em caruru. A soja foi mais competitiva que caruru até os 33 dias após o plantio. Acido ferúlico afetou a competitividade de caruru em maior grau do que a de soja.

Palavras-chave: Glycinemax Amaranthus retroflexus, alelopatia, interferência.

\section{ABSTRACT}

\section{Soybean and redroot pigweed density interactions as affected by ferulic acid}

A replacement series experiment under greenhouse conditions was carried out to evaluate the effects of ferulic acid (4-hydroxy-3-methoxy-t-cinnamic acid) on soybean [Glycine max (L.) Merr. cv. Bragg] and redroot pigweed (Amaranthus retroflerus L.) plant density combinations. Soybeans and redroot pigweed were combined at 4:0, 3:2, 2:4, 1:6 and 0:8 plants per pot. Ferulic acid dosages used were zero, 500 and $1000 \mathrm{ppm}$. A randomized block design with four replications was used. The duration of the experiment was 33 days. For ferulic acid dosages of 500 and 1000 ppm, delays in soybean emergence of 2 and 3 days respectively were observed. Soybean plant height was increased at

\section{INTRODUÇÃO}

Experimentos de substituição de plantas em séries têm sido usados para estudar interferência entre diferentes espécies de plantas (Christie \& Detling, 1982; Elmore et al.,

1 Recebido para publicação em 21/03/93 e na forma revisada em 20/06/93. 2 Pesquisador da EMBRAPA/CNPSo, Caixa Postal 1061, CEP 86001-970, Londrina, $\mathrm{PR}$ lower soybean:pigweed rates and at higher ferulic acid dosages; the opposite was observed in pigweed. Soybean shoot and root dry weights decreased as the number of soybeans plants increased, in contrast to pigweed. Higher doses of ferulic acid reduced shoot dry weight and relative total yield of pigweed. Intraspecific competition in pure stands was higher for soybeans than pigweed. Soybeans were more competitive than pigweed up to the harvest time at 33 days. Ferulic acid affected redroot pigweed competitiveness to a much higher degree than that of soybeans.

Additional index words: Glycine max, Amaranthus retroflexus, allelopathy, interference.

1983; Flint \& Patterson, 1983; Harper, 1977). Desenhos aditivos também têm sido usados (Harper, 1977), envolvendo efeitos de plantas daninhas sobre as culturas, sob condições de campo. Em experimentos aditivos, a proporção de uma espécie de planta (daninha) para uma outra (cultura) e a densidade total da mistura variam simultaneamente e os efeitos dos dois fatores não podem ser separados. Nos experimentos de substituição em séries, a densidade total é mantida constante, enquanto variam as proporções de ambas as espé-

Planta Daninha, v. 11, n. 1/2, 1993. 
cies. Isto nos permite identificar a "competitividade" de ambas as espécies sob determinadas condições, que pode tomar distintas formas básicas ou modelos (Harper, 1977).

Caruru (Amaranthus spp) aparece repetidamente na lista das plantas daninhas mais comuns no sul do Brasil. Moolani et al. (1964) observaram reduções máximas de 39\% na produção de milho e de $55 \%$ na soja, em competição com caruru. A biomassa seca total de milho mais caruru foi relativamente constante sob diferentes níveis de competição. Em relação a soja, caruru cresceu mais alto, e o peso da biomassa seca da cultura mais caruru foi $33 \%$ maior que a da cultura isolada.

Pelo lado fisiológico, em relação à fotossíntese, a soja é uma planta C3 (Black et al., 1969) e caruru, uma planta C4 (Bloch et al., 1969; Patterson, 1976). Flint e Patterson (1983), baseados em produção de matéria seca, observaram que em todas as temperaturas testadas, soja (planta C3) foi superior a Amaranthus sp. (planta C4), no $34^{\circ}$ dia. Menor peso de sementes sugeriu que a espécie seria um competidor menos eficaz que a soja. Pearcy et al. (1981) mostraram que espécies $\mathrm{C} 4$, co mo Amaranthus, tinham vantagen $\mathrm{s}$ competitivas sob temperaturas altas, e espécies C3, como Chenopodium, tinham vantagens sob temperaturas baixas.

DeWitt (1960), num experimento de substituição em séries, com combinações de aveia e cevada, em campo, mostrou que o "coeficiente relativo de populações máximas" de aveia sobre cevada mudou de 0,9 a 20 , ao testar diferentes tratamentos de fertilidade, o que acarretou distintas mudanças de $\mathrm{pH}$ no solo.

Interferência entre espécies de plantas, como resultado de lixiviação ou de exsudatos de raízes no solo, tem mostrado muitos efeitos que podem alterar a competitividade entre es pécies de plantas. Bhow mik \& Doll (1982) mostraram que extratos de caruru (Amaranthus retroflexus) eram capazes de inibir a elongação do hipocótilo na soja, tendo causado reduções de $14 \%$ no rendimento. Williams \& Hoagland (1982) mostraram que a germinação do caruru foi afetada pelo ácido ferúlico na concentração de $10^{\prime 3} \mathrm{M}$. Eles observaram também que caruru foi a espécie mais afetada no crescimento entre as oito espécies testadas. Esta sensibilidade poderia estar diretamente relacionada com o seu menor tamanho de sementes, também observado por Flint e Patterson (1983). Patterson (1981) relata que a produção da matéria seca de soja, após três semanas de crescimento, foi significativamente reduzida na presença de ácido ferúlico na concentração $10-{ }^{3} \mathrm{M}$, em solução nutritiva.

O objetivo deste experimento foi avaliar a competitivídade das espécies de plantas de soja e caruru, num modelo competitivo de substituição das plantas em série, na presença de um fator alelopático.

\section{MATERIAL E MÉTODOS}

Um experimento foi conduzido em casa-de-vegetação, num arranjo de cínco densidades de plantas, com substituição de plantas de soja [Glycine max (L.) Merr. cv. Bragg] por plantas de caruru (Amaranthus retroflexus L.), nas proporções de 4:0, 3:2, 2:4, 1:6 e 0:8 (modelo substitutivo), combinadas com três doses de ácido ferúlico (AF) (ácido-4- hidróxi-3-metóxi-t-cinâmico) de zero, 500 e 1000 ppm. A duplicação do número de plantas de caruru teve por objetivo equilibrar vantagens competitivas iniciais que a soja teria sobre a espécie. O delineamento experimental foi o de blocos ao acaso, num esquema fatorial $5 \times 3$, com quatro repetições. O plantio foi feito em vasos $(1000 \mathrm{ml})$ de papel encerado perfurados na base para drenagem e preenchidos com uma mistura de solo $2: 1(\mathrm{v} / \mathrm{v})$ de areia e argila. As respectivas doses de ácido ferúlico (pó) foram pesadas e adicionadas diretamente ao solo seco ao ar e bem misturadas. Os vasos foram irrigados com água de torneira até atingir a capacidade de campo do solo e plantados no dia seguinte. As sementes de soja e caruru e suas combinações foram plantadas em quatro pontos eqüidistantes no vaso, em seqüência, a 2,0 e $0,5 \mathrm{~cm}$ de profundidade, respectivamente. As sementes de soja semeadas eram de aparência uniforme e sadia. Sete dias após, as plântulas de soja e caruru foram raleadas para as proporções previamente estabelecidas. A umidade do solo foi restabelecida ao atingir $50 \%$ da capacidade de campo. Uma vez por semana, $100 \mathrm{ml}$ da solução de Hoagland foram adicionados aos vasos para suprir os nutrientes necessários às plantas. A duração do experimento foi de 33 dias.

As determinações consistiram de: a) observações sobre a emergência e crescimento das espécies; b) altura das plantas, em mm, medida da base no solo até a base dos brotos terminais, aos 14 e 33 dias após o plantio (DAP); c) biomassa seca da parte aére a e das raízes da soja e biomassa seca apenas da parte aérea do caruru, visto que as raízes da soja sofreram consideráveis perdas por ocasião da sua separação do solo. A parte aérea das plantas foi cortada rente ao solo e as raízes da soja cuidadosamente separadas do solo através de lavagens com água. A parte aérea e as raízes das plantas foram colocadas em sacos de papel e secadas até peso constante. As biomassas secas foram determinadas em balança de precisão até $0,01 \mathrm{~g}$.

As biomassas secas totais da parte aérea, por espécie de planta/vaso, foram usadas para calcular produções relativas (PR) para todas as proporções de plantas, baseadas na biomassa do estande puro de cada espécie. Estas produções foram indicadas em diagramas para uma análise das mesmas e das suas produções totais relativas (PTR).

Os dados de cada variável foram submetidos à análise da variância e ao teste F. Foram realizados inicialmente os testes de normalidade dos resíduos (Lilliefors) e homogeneidade de variância (Burr-Foster). Em função de o coeficiente de variação ser alto, optou-se pela transformação dos dados em raiz quadrada de $x$, o que não afetou os resultados do teste de Burr-Foster. Os dados de altura de plantas não foram transformados. A análise de regressão foi executada para parâmetros significativos pelo teste F. Para efeitos significativos de interação de fatores aplicou-se o teste de Tuckey a $5 \%$.

\section{RESULTADOS E DISCUSSÃO}

A germinação da soja não foi afetada pelos aumentos nas doses de ácido ferúlico (AF), o que não pôde ser medido em caruru, semeado em excesso. Soja e caruru apresentaram um atraso de 2 e 3 dias na germinação, nas doses de 500 e 
1000 ppm de AF, respectivamente. Uma observação visual feita em plantas extras, removidas aos dez dias, mostrou uma redução das raízes de soja de cerca de $50 \%$ em presença de 500 ppm de AF com grande profusão lateral de raízes, sendo mais acentuada com a dose de $1000 \mathrm{ppm}$. Aos 15 dias as plantas de soja apresentaram um leve amarelecimento na ponta das folhas, que desapareceu cinco dias após. Bhowmik \& Doll (1982) confirmam semelhante redução, enquanto que Williams \& Hoagland (1982) observaram redução na germinação de caruru.

Na Figura 1, observa-se que a altura de plantas de soja decresceu com o aumento das proporções de soja em relação a caruru. Para este, ao contrário, houve um aumento na altura de plantas, que aos 14 dias apresentava um decréscimo.

Na Figura 2, observa-se que a altura de plantas de soja

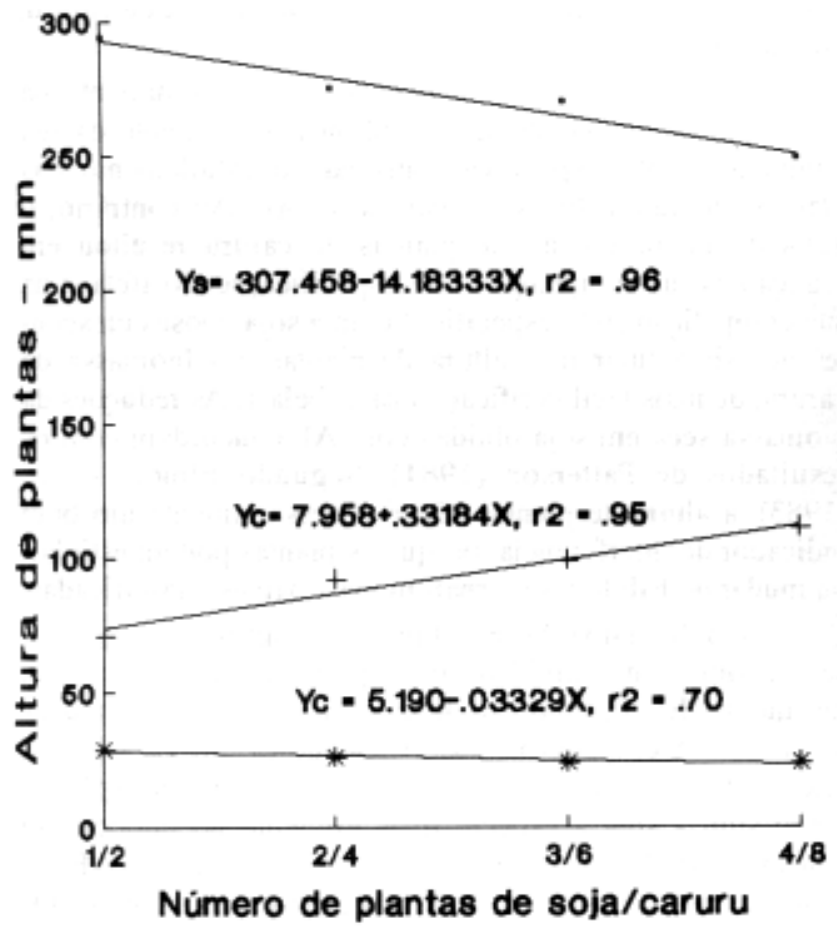

FIG. 1 - Efeitos do modelo substitutivo de competição de soja (s) e caruru (c), sobre a altura da planta de soja aos 33 dias (\#) e de caruru aos 33 (+) e $14\left(^{(*)}\right.$ dias. Dados de caruru raiz de $x$.

aumentou com doses crescentes de $\mathrm{AF}$, enquanto que caruru decresceu, o que já foi constatado aos 14 dias.

Na Figura 3, observa-se que as biomassas secas da parte aérea e da raiz da soja diminuíram com o aumento da proporção de plantas de soja. Por sua vez, a biomassa seca da parte aérea de caruru aumentou com maiores proporções da espécie.

Na Figura 4, observa-se que as biomassas secas da parte aérea de soja e caruru decresceram com os aumentos das doses de ácído ferúlico.

Na Tabela 1, são apresentados os resultados de interações significativas entre proporções de plantas de soja:caruru e $\mathrm{AF}$, observados para a biomassa seca da parte aérea e altura de plantas de caruru. Observa-se que, à medida que o número de plantas de caruru aumentou em relação ao de soja, ocorreu um aumento significativo de biomassa seca/planta na ausên-

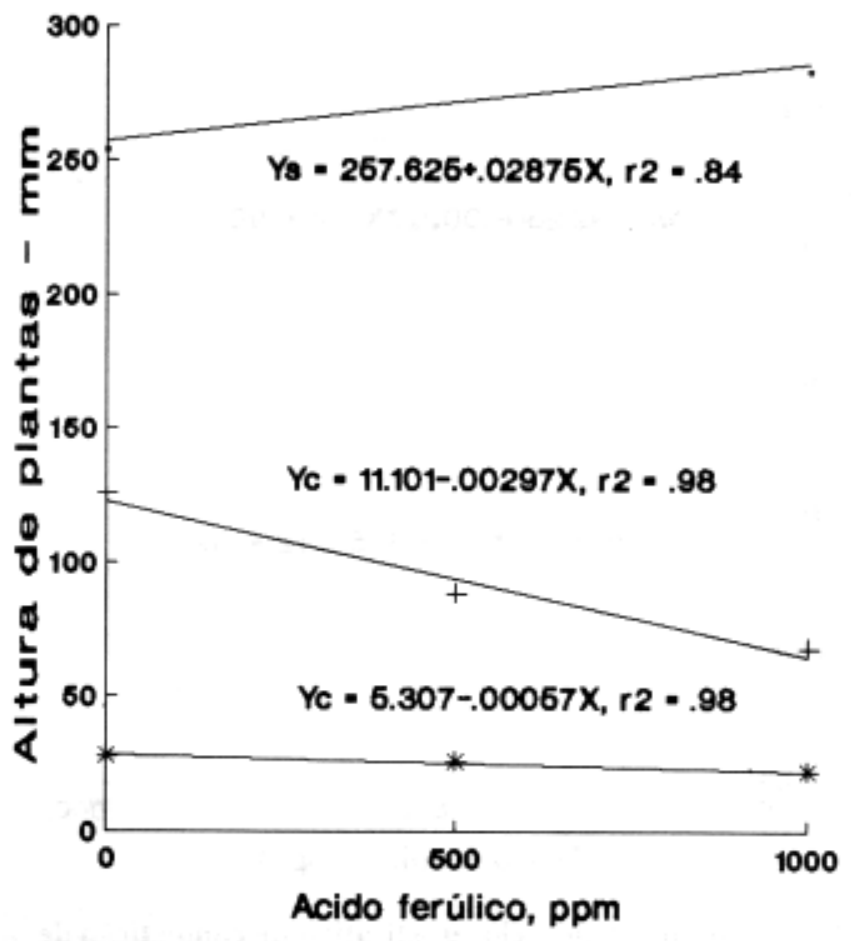

FIG. 2 - Efeitos do modelo substitutivo de competiçáo de soja (s) e caruru (c), em interação com doses de ácido ferúlico, sobre a altura da planta de soja aos 33 dias (\#) e de caruru aos 33 (+) e $14\left(^{(*)}\right.$ dias. Dados de caruru raiz de $x$.

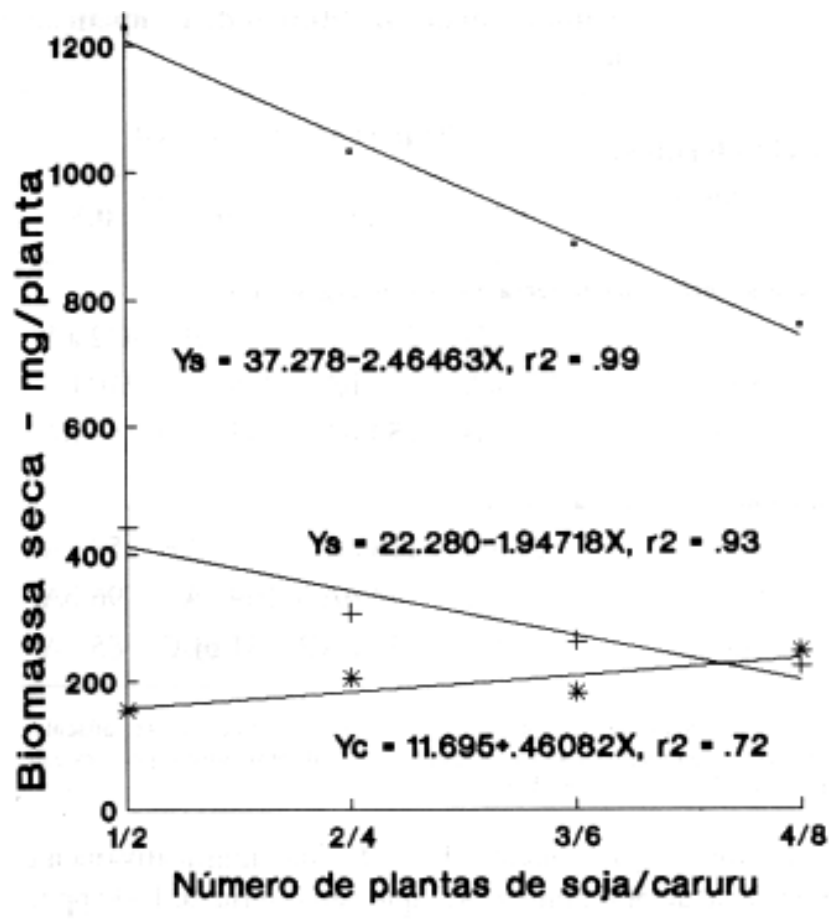

FIG. 3 - Efeitos do modelo substitutivo de competição de soja (s) e caruru (c) sobre a biomassa seca da parte aérea (\#) e raiz (+) de soja e da parte aérea de caruru (*), aos 33 dias. 


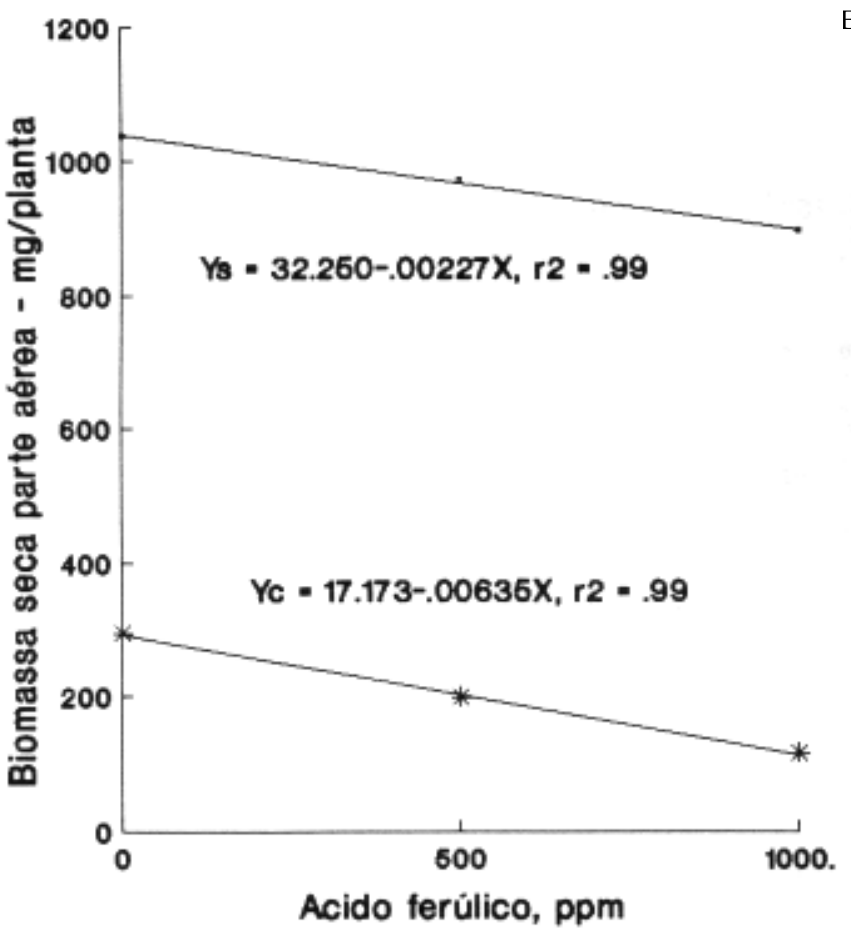

FIG. 4 - Efeitos do modelo substitutivo de competição de soja (s) e caruru (c), em interaçāo com doses de ácido ferúlico, sobre a biomassa seca da parte aérea de soja (\#) e de caruru (*), aos 33 dias.

TABELA 1 - Biomassa seca da parte aérea e altura de plantas de caruru, aos 33 dias após o plantio, nas interaçōes de doses de ácido ferúlico com proporçôes de plantas de soja:caruru, em um modelo substitutivo de competiçáo, em vasos.

\begin{tabular}{c|c|c|c|c}
\hline \multirow{2}{*}{$\begin{array}{c}\text { Ácido ferúlico } \\
\text { (ppm) }\end{array}$} & \multicolumn{5}{c}{ Proporção soja:caruru } \\
\cline { 2 - 5 } & $\mathbf{3 : 2}$ & $\mathbf{2 : 4}$ & $\mathbf{1 : 6}$ & $\mathbf{0 : 8}$ \\
\hline Biomassa seca da parte aérea do caruru (mg/planta) \\
0 & $232 \mathrm{aB}$ & $277 \mathrm{aB}$ & $260 \mathrm{aB}$ & $422 \mathrm{aA}$ \\
500 & $178 \mathrm{aA}$ & $190 \mathrm{bA}$ & $215 \mathrm{aA}$ & $210 \mathrm{bA}$ \\
1000 & $76 \mathrm{bB}$ & $154 \mathrm{bA}$ & $95 \mathrm{bAB}$ & $150 \mathrm{bA}$ \\
& & & & \\
Altura de plantas de caruru (m m) & & & & \\
0 & $97 \mathrm{aC}$ & $118 \mathrm{aBC}$ & $133 \mathrm{aAB}$ & $158 \mathrm{aA}$ \\
500 & $68 \mathrm{bB}$ & $84 \mathrm{bAB}$ & $109 \mathrm{aA}$ & $96 \mathrm{bA}$ \\
1000 & $52 \mathrm{bC}$ & $75 \mathrm{bAB}$ & $61 \mathrm{bBC}$ & $85 \mathrm{bA}$ \\
\hline
\end{tabular}

${ }^{1}$ Médias dentro de cada parâmetro seguidas pelas mesmas letras minúsculas na vertical, ou maiúsculas na horizontal, náo diferem entre si pelo teste de Tuckey a 5\% de probabilidade.

cia de soja que, no entanto, foi reduzida significativamente coma dose de 500 ppm de AF, que não diferiu de 1000 ppm. Os efeitos tenderam a não ser significativos entre as proporções de plantas nos níveis de AF. Por sua vez, os efeitos de ambos os fatores foram acentuados para a altura de plantas. Enquanto a biomassa seca da parte aérea e altura de
E. Vai1

plantas aumentaram com maiores proporções de plantas de caruru, ambos foram reduzidos na presença de AF.

Na Figura 5, são apresentados diagramas de produções relativas (PR) e produções totais relativas (PTR) de soja e caruru. $\mathrm{Na}$ ausência de $\mathrm{AF}$, as $\mathrm{PR}$ das populações puras são iguais a $100 \%$. As PR esperadas, na ausência de AF, são re presentadas por linhas retas tracejadas, que se cruzam. Com as substituições proporcionais do número de plantas de ambas as espécies, as biomassas secas da parte aérea da soja foram maiores do que as esperadas e menores para caruru. $\mathrm{Na}$ ausência de AF, as PTR (tinidas por uma linha reta contínua) foram aproximadamente iguais a $100 \%$, exceto no proporção de soja:caruru de 1:6, com maior depressão sobre caruru, que deveria ter se aproximado da população pura. Nos diagramas seguintes, observa-se que o AF, nas doses de 500 a 1000 ppm, afetou progressivamente as PR de caruru, afetando pouco as de soja.

Nas Figuras de 1 a 4, observa-se que o aumento da proporção de plantas de soja resultou num aumento da sua competição intra-específica, causando o estiolamento das plantas, devido a doses crescentes de AF. Ao contrário, o aumento da proporção de plantas de caruru resultou em redução da sua competição intra-específica, sendo afetada na sua competição (interespecífica) com a soja. Doses crescentes de AF reduziram a altura de plantas e a biomassa de caruru, de mais fácil verificação na Tabela 1 . As reduções da biomassa seca em soja obtidas com AF concordam com os resultados de Patters on (1981). Segundo Elmore et al. (1983), a altura de plantas não é necessariamente um bom indicador de interferência, porque as plantas podem estiolar, ou mudar de hábito e se tornarem mais baixas e ramificadas.

Pelo diagrama $\mathrm{AF}=0,0 \mathrm{ppm}$, da Figura 5, comprova-se a maior competitividade da soja em relação ao caruru, mesmo usado na proporção de uma planta de soja para duas de caruru. A competição observada indica que os mesmos fatores do meio foram explorados por ambas as espécies, tendo sido a soja a espécie mais eficiente no período em consideração. Nos diagramas seguintes, observa-se o AF nas doses de 500 a $1000 \mathrm{ppm}$ afetando progressivamente as PR de caruru pouco as de soja, que se mantêm acima do es perado. Em função dos maiores efeitos sobre o caruru, as PTR foram menores com o aumento da proporção de plantas de caruru para soja.

A literatura apresenta evidências de que a maior habilidade da soja (planta C3) em competir com caruru (planta C4) pode estar relacionada ao maior tamanho de sementes da soja em relação às de caruru e ao curto período inicial de crescimento submetido (Elmore et al., 1983). Igual suposição tem sido usada para justificar a maior sensibilidade do caruru ao AF (Williams \& Hoagland, 1982). Contudo, extratos de caruru têm afetado o crescimento da soja (Bhowmik \& Doll, 1982). Caruru é suposto ter vantagens competitivas sobre a soja num estádio mais adiantado do crescimento da soja (Moolani et al., 1964), por crescer mais alto e ser favorecido por temperaturas mais elevadas (Patterson, 1981; Pearcy et al., 1981), como parece ocorrer em plantios mais tardios.

Quantidades de substâncias alelopáticas obtidas por extração em água, como o AF, detectadas no solo em áreas de plantio de cana-de-açúcar, têm variado de $5,8 \mathrm{ppm}$ (Whitehead, 1974) a 12,6 ppm (Wang et al., 1967) e depen- 

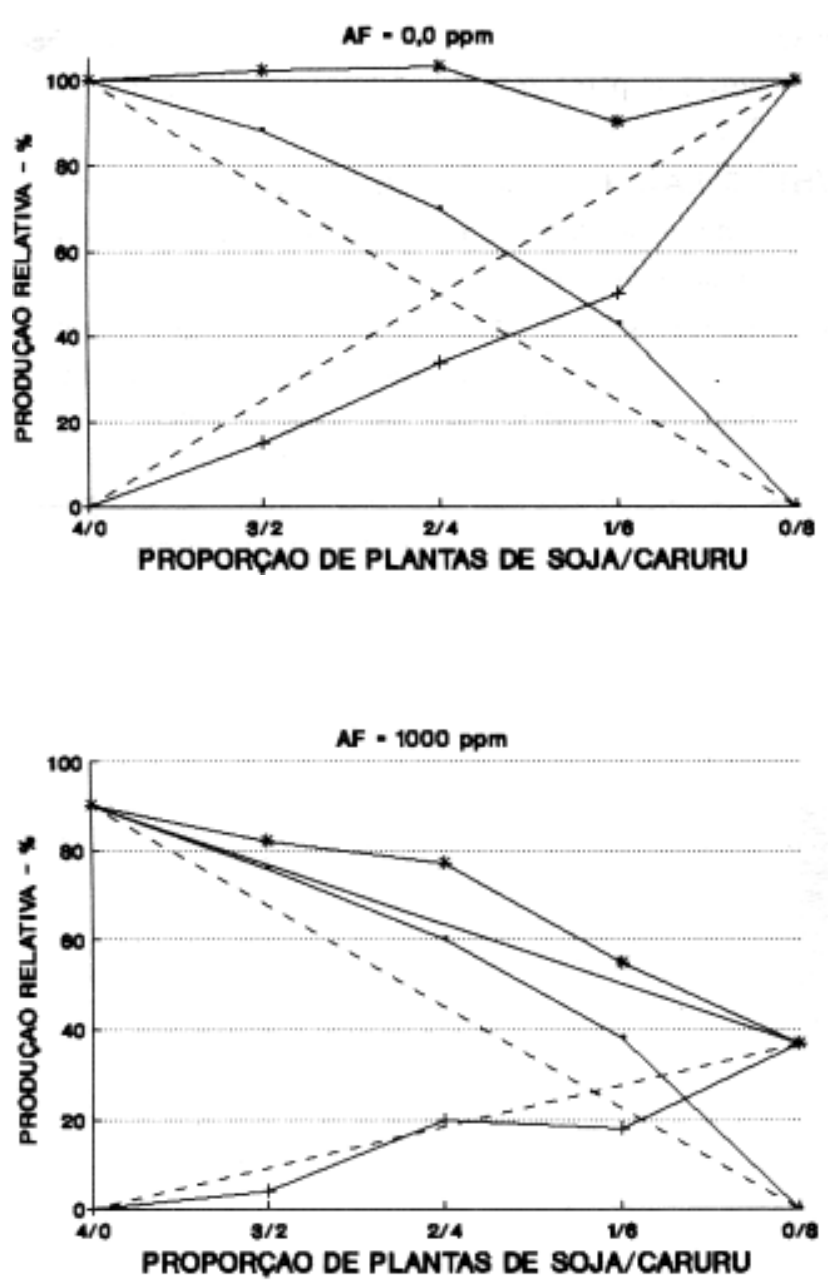

dem das condições de meio e da época de determinação. Sugere-se que mesmo baixas concentrações destas substâncias podem agir sinergicamente com outros compostos fenólicos para inibir a germinação (Rasmussen \& Einhelling, 1977; Williams \& Hoagland, 1982) e crescimento das plântulas (Rasmussen \& Einhelling, 1977) de diferentes espécies de plantas.

Sendo a soja mais competitiva que o caruru nos primeiros 30 dias do seu ciclo, observa-se a importância do estabelecimento de bons estandes de soja e o plantio na época mais adequada, bem como a manutenção de restevas de culturas, que liberam substâncias alelopáticas e proporcionam sombreamento, no controle de espécies como caruru.

\section{LITERATURA CITADA}

BHOWMIK, P.C. \& DOLL, J.D. Corn and soybean response to alelopathic effects on weed and crop residues. Agronomy Journal, 74: 601-606, 1982.

BLACK, C.C.; CHEN, T.M. \& BROWN, R.H. Biochemical basis for plant competition. Weed Science, 17: 338344, 1969.

CHRISTIE, E.K. \& DETLING, J.K. Analysis of interference between $\mathrm{C} 3$ and $\mathrm{C} 4$ grasses in relation to temperature

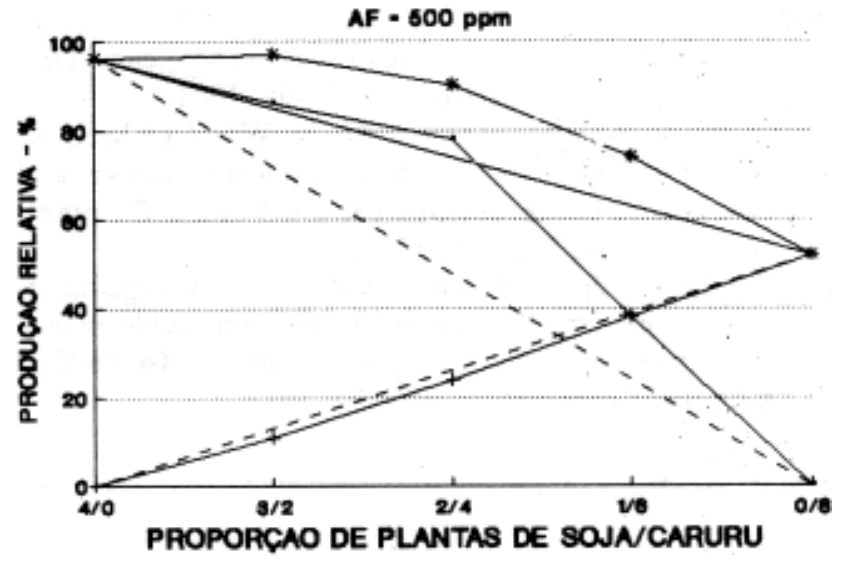

FIG. 5 - Diagramas de produçōes relativas (+) e produçōes totais relativas (*) para biomassa aérea de soja e caruru nas interaçōes de ácido ferúlico (AF) e proporçóes de plantas, aos $\mathbf{3 3}$ dias após o plantio.

and soil nitrogen supply. Ecology, 63:1277-1284, 1982.

DeWITT, C.T. On competition. Versl. Landbowkd. Onderz., 66: 1-82, 1960.

ELMORE, C.D.; BROWN, M.A. \& FLINT, E.P. Early interference between cotton (Gossypium hirsutum) and four weed species. Weed Science, 31: 200-207, 1983.

FLINT, P.E. \& PATTERSON, D.T. Interference and temperature effects on growth in soybean (Glycine max) and associated C3 and C4 weed. Weed Science, 31: 193-199,1983.

HARPER, J.L. Population biology of plants. Academic Press, London, 1977. 892p.

HOAGLAND, D.R. \& ARNON, D.I. The water culture method for growing plants without soil. Calif. Agric. Exp. Sta. Circ. $N^{\circ}$ 547.32p., 1950.

MOOLANI, M.K.; KNAKE, E.L. \& SLIFE, F.W. Competition of smooth pigweed with corn and soybeans. Weeds, 12: 126-128, 1964.

PALMER, R.D. Category I. Weed Survey. Southern States. Res. Rep. South. Weed Science Society, 33: 165-197, 1980.

PATTERSON, D.T. C4 photosynthesis in smooth pigweed. Weed Science, 24: 127-130, 1976. 
PATTERSON, D.T. Effects of allelopathic chemicals on growth and physiological responses on soybeans (Glycine $\max$ ). Weed Science, 29: 53-59, 1981.

PEARCY, R.W.; TUMOS A, N. \& WILLIAMS, K. Relationship between growth, photosynthesis and competitive interactions for a C3 and a C4 plant. Oecology, 48: 371-376, 1981.

RASMUSSEN, J.S. \& EINHELLING, F.A. Synergistic inhibitory effects of p-coumaric and ferulic acids on germination and growth of grain sorghum. Journal of Chemical Ecology, 3: 197-205, 1977.
WANG, T.S.C.; YANG, T.K. \& CHUANG, T.T. Soil phenolics as plant growth inhibitors. Soil Science, 103: 239-246,1967.

WHITEHEAD, D.C. Identification of p-hidroxi-benzoic, vanillic, p-coumaric, and ferulic acids in soils. Nature, London, 202: 417-418, 1974.

WILLIAMS, R.D. \& HOAGLAND, R.E. The effects of naturally occurring phenolic compounds on seed germination. Weed Science, 30: 206-212, 1982. 